\title{
On-Campus Occupational Therapy Clinic Enhances Student Professional Development and Understanding
}

Kelly Erickson

The College of St. Scholastica

Follow this and additional works at: https://encompass.eku.edu/jote

Part of the Occupational Therapy Commons, and the Scholarship of Teaching and Learning Commons

\section{Recommended Citation}

Erickson, K. (2018). On-Campus Occupational Therapy Clinic Enhances Student Professional Development and Understanding. Journal of Occupational Therapy Education, 2 (2). https://doi.org/10.26681/jote.2018.020202

This Original Research is brought to you for free and open access by Encompass. It has been accepted for inclusion in Journal of Occupational Therapy Education by an authorized editor of Encompass. For more information, please contact Linda.Sizemore@eku.edu. 


\title{
On-Campus Occupational Therapy Clinic Enhances Student Professional Development and Understanding
}

\begin{abstract}
Changing healthcare systems impact clinical sites that provide fieldwork for occupational therapy programs and require students to be prepared for the pace and demands of the clinical settings. Occupational therapy programs strive to enhance hands-on experiences in didactic curriculum to better prepare students for Level II fieldwork. An on-campus clinic course was implemented over two semesters with students engaging in the occupational therapy process with adult and pediatric clients from the community under the supervision of faculty. Student surveys and focus group data were analyzed over five years. Survey responses to open-ended question were triangulated with data from focus group results and themes were validated with quantitative survey data. The research explored the design of the on-campus clinic courses, the themes of the data analysis, and implications for learning opportunities with clients in an on-campus experience. The findings support the feasibility of implementing an on-campus clinic with positive student outcomes and enhanced faculty-student relationships that are sustainable over several years.
\end{abstract}

\section{Keywords}

Experiential, professionalism, on-campus clinic, faculty role model, hands-on learning

\section{Creative Commons License} (c) (1) (9)

This work is licensed under a Creative Commons Attribution-Noncommercial-No Derivative Works 4.0 License.

\section{Acknowledgements}

Special thanks to Nancy Gabres and Rondell Berkeland as the developers of the on-campus clinic courses. Also to Justine Ossman and Laura Sampers for their diligent work in preparing the literature review. 


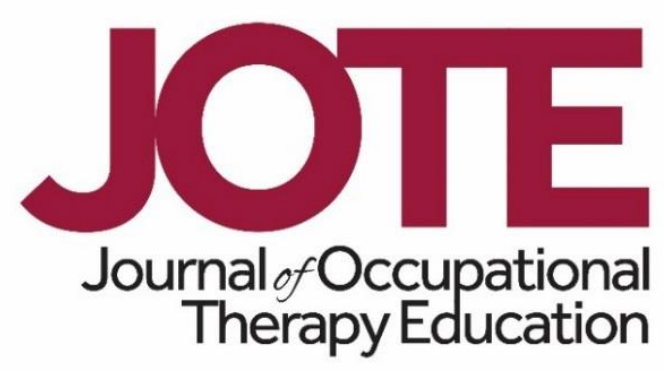

Volume 2, Issue 2

\title{
On-Campus Occupational Therapy Clinic Enhances Student Professional Development and Understanding
}

\author{
Kelly Erickson, PhD, OTR/L \\ The College of St. Scholastica \\ United States
}

\begin{abstract}
Changing healthcare systems impact clinical sites that provide fieldwork for occupational therapy programs and require students to be prepared for the pace and demands of the clinical settings. Occupational therapy programs strive to enhance hands-on experiences in didactic curriculum to better prepare students for Level II fieldwork. An on-campus clinic course was implemented over two semesters with students engaging in the occupational therapy process with adult and pediatric clients from the community under the supervision of faculty. Student surveys and focus group data were analyzed over five years. Survey responses to open-ended question were triangulated with data from focus group results and themes were validated with quantitative survey data. The research explored the design of the on-campus clinic courses, the themes of the data analysis, and implications for learning opportunities with clients in an on-campus experience. The findings support the feasibility of implementing an on-campus clinic with positive student outcomes and enhanced faculty-student relationships that are sustainable over several years.

\section{INTRODUCTION}

Occupational therapy curricula traditionally rely on fieldwork experiences to provide practice-ready skills. The rapid growth of occupational therapy programs, limited numbers of qualified fieldwork educators, and greater competition for clinical sites suggests clinical opportunities in academic settings are needed (American Occupational Therapy Association Fieldwork Ad Hoc Committee, 2017; Peloquin \& Osborne, 2003). The value of experiential learning that engages the student and requires generation of new ideas has been found extensively in literature across curriculums (Kinchin, Baysan, \& Cabot, 2008; Nolinske \& Millis, 1999).
\end{abstract}




\section{LITERATURE REVIEW}

\section{Occupational Therapy Experientials within Curricula}

Occupational therapy curricula include experiential learning with clients for hands-on practice to bridge the gap between theory and clinical skills and to allow students to get an understanding of clients earlier in the program (Benson, Provident, \& Szucs, 2013; Coker, 2010; Goldbach \& Stella, 2017; Knecht-Sabres, 2013; Phillips, 2017). Many of these experientials are established in addition to the required Level I fieldwork experiences and involve actual clients that occur within the campus setting or in partnership with a community site. Four studies used community settings to carry out the courses (Benson, Provident, \& Szucs, 2013; Falk-Kessler, Benson, \& Witchger Hansen, 2007; Knecht-Sabres, 2013; Phillips, 2017), one study used an on-campus clinic (Goldbach \& Stella, 2017), and one did not identify whether the experiential occurred on-campus or in the community (Coker, 2010). All studies had faculty responsible for setting up the client sessions, administering day-to-day operations of the experience, and providing direct supervision and teaching of students. Three components were identified as relevant to the planning and implementation of occupational therapy experientials with clients: reflection, student-faculty relationship, role of the faculty, and barriers (Benson et al., 2013; Coker, 2010; Falk-Kessler et al., 2007; Goldbach \& Stella, 2017; Knecht-Sabres, 2013; Phillips, 2017).

Reflection. Assessing assumptions is an essential component of experiential clinics for occupational therapy students with evidence supporting reflection as an effective tool for professional growth (Benson et al., 2013; Coker, 2010; Falk-Kessler et al., 2007; Goldbach \& Stella, 2017; Knecht-Sabres, 2013; Phillips, 2017). In experiential learning, the reflection process serves several purposes to facilitate adult learning by internalizing learning (Kolb \& Kolb, 2005). Students and instructors must analyze experiences to challenge beliefs and to contemplate other ways of thinking. Students have time to consider feedback and change their actions accordingly in order to improve their performance. Students are able to implement necessary changes based on their personal findings and feedback from the faculty, thus enhancing their application of clinical reasoning and techniques (Lee, 2007). Reflection in occupational therapy experientials with clients included one-on-one consultation and small and large group discussion with students and faculty as well as independent journaling that enabled student self-reflection (Benson et al., 2013; Falk-Kessler et al., 2007; Goldbach \& Stella, 2017; Knecht-Sabres, 2007; Phillips, 2017). A student's ability to use reflection improved in several studies as reported by students being able to implement change in clinical reasoning and during actual intervention sessions (Benson et al., 2013; Coker, 2010; Goldbach \& Stella, 2017; Knecht-Sabres, 2007).

Student-faculty relationship. Faculty and students had a direct working relationship in the experientials with clients including meetings between faculty and student before and/or after clinic sessions, students submitting documentation to faculty for review, and individual or group faculty to student supervision pairings (Benson et al., 2013; FalkKessler et al., 2007; Golbach \& Stella, 2017; Knecht-Sabres, 2013; Phillips, 2017). The student-faculty relationship served four main purposes: collaboration, feedback, serving as role model, and connecting theory to practice. 
The partnership between the student and faculty member is critical to the learning process as students gain knowledge and skills through feedback from the faculty member on a student's performance and clinical reasoning (Falk-Kessler et al., 2007; Knecht-Sabres, 2013). Faculty served as role models for the students by demonstrating skills in interactions, as well as supervising the clinic interventions during the experiential learning opportunity (Benson et al., 2013; Falk-Kessler et al., 2007; Golbach \& Stella, 2017). The ability to link course objectives to actual client experiences resulted in perceived and measurable improvements in clinical reasoning for students (Falk-Kessler et al., 2007; Knecht-Sabres, 2013).

Role of faculty. The main role of faculty in an experiential learning opportunity with clients is that of teacher (Falk-Kessler et al., 2007; Haertl, 2008; Knecht-Sabres, 2013; Phillips, 2017). The demand on time for faculty involved in the experiential clinic within didactic courses requires faculty be explicit about their availability and give students their full attention during meeting times in order to maintain an effective instructorstudent relationship (Haertl, 2008; Knecht-Sabres, 2013). The administrative role of faculty has been identified as maintaining a client population, establishing the clinic schedule, and managing financial needs of the clinic (Knecht-Sabres, 2013).

Barriers. Despite the many benefits of experientials with clients, barriers exist when implementing and maintaining the experientials, which can often add to the demands on faculty time. Programs implementing experiential learning involving clients and occupational therapy students within curricula should maintain an appropriate client population, facilitate financial management, and schedule time for educators, students, and facilities (Falk-Kessler et al., 2007; Knecht-Sabres, 2013). Time constraints of the course and semester were also identified as a barrier (Phillips, 2017); experiential sites located off-campus require time for getting to the site and transportation for students (Falk-Kessler et al., 2007; Knecht-Sabres, 2013). Back-up plans were also essential in the event of client cancellations so students had equitable numbers of clinic experiences (Knecht-Sabres, 2013). Healthy client populations were found to be a barrier as students had difficulty identifying actual needs of the clients to set measurable goals (Phillips, 2017).

\section{ON-CAMPUS CLINIC MODEL COURSE DESIGNED FOR IMPLEMENTATION}

The experiential learning opportunity in this study was implemented as an on-campus clinic course occurring in an occupational therapy master's program at a Midwestern private college. The on-campus clinic was concurrent with didactic occupational therapy courses in each semester. The on-campus clinic started in 2002 through a 3M Foundation Vision Grant as an opportunity to serve the community and provide handson experiences for students when the cohort size of the program was small. The clinic was initially supported for five years through this grant and has since been supported by tuition and nominal access fees charged to clients.

The on-campus clinic was held within the classrooms located in the occupational therapy department. Implementing an on-campus clinic allowed the program to individualize the learning of students by emphasizing both clinical skills and professional 
behaviors. The model consisted of second-year graduate students participating in a course with an adult clinic in one semester followed by a pediatric clinic in the next semester.

The adult clinic experience involved paired student learning experiences with students sharing evaluation and intervention planning for one client over the course of ten to twelve weeks. In the pediatric clinic experience, students transitioned to independent client interactions with shared initial evaluations and intervention planning on their own. This was a natural progression of student skills as they gained confidence through collaboration with another student. Students were responsible for weekly documentation including attendance verification and SOAP notes. Students collaborated to complete an initial evaluation and discharge plan for a shared client.

Students received feedback on clinical skills in sessions and documentation, which was submitted weekly to the faculty for the clinic. One adjunct faculty supervised the students in the clinic and one full-time faculty taught the companion didactic course. The adjunct faculty supervised the clinic sessions and met weekly with student pairs to discuss planned interventions and identify clinical skills and professional behaviors needing improvement. Reflection was built into the course design from experiential learning theory (Kolb \& Kolb, 2005) with the expectation that students have the concrete experience of evaluation and intervention with a client, reflect on their performance, create a new plan for the next session, and retest that plan in the following session. Students were assessed in the clinic by faculty with a self-designed evaluation form that measured clinical skills and professional behaviors.

\section{METHODS}

The current study had three aims: to explore students' perceptions of their professional growth from participating, to determine the role of faculty as clinical educators in developing that professional growth, and to identify the sustainability of these outcomes across five years of on-campus clinics. An exploratory study design was conducted across five academic years. Institutional Review Board at this Midwestern private college determined the project exempt due to data being collected as part of classroom instruction under the supervision of course faculty. The study design included a selfdesigned survey and a focus group.

Students enrolled in the second year of the graduate occupational therapy program participated in the on-campus clinic as part of a required course in both fall and spring semesters. Surveys and focus groups were administered at the completion of the 12week clinic experiences. Survey responses were gathered in the first semester of adult on-campus clinic $(n=124)$ and in the second semester of pediatric on-campus clinic $(n$ $=129$ ). Participation in the surveys was voluntary and not all participants completed the surveys in both semesters. Participation in the focus groups was mandatory and faculty attempted to elicit comments from all participants during the focus groups with 91 students participating in each semester focus group. 
The survey was self-designed through multiple faculty input with the goal of informing future clinic designs and ensuring student learning needs were being met. While it is acknowledged that a self-designed survey does not ensure valid and reliable data, the emphasis in this survey design was gathering descriptive data to explore students' learning experiences in the clinic course. The survey included both quantitative and qualitative questions and was delivered after each clinic course with anonymous responses from student participants. Survey content included the orientation process to the on-campus clinic, students' perceptions of faculty in supervising, personal reflections, and recommendations. Orientation process data were not analyzed with this study.

Open-ended questions in the survey explored students' perceived growth as an occupational therapy professional through the on-campus clinic experience. Students also responded to an open-ended question about how the clinic experience enhanced learning and application of material from didactic courses. Likert-scale rankings for level of agreement with 15 statements were used to measure students' perceptions of the faculty involved in supervising clinic sessions. Frequencies and means were calculated using Excel data analytics.

A two-hour focus group was also held at the conclusion of each on-campus clinic that gathered qualitative information exploring what went well within the clinic experience, identification of problems and challenges within the clinic, students' plans to modify performance in future fieldwork experiences, and ideas for modification of the format for future on-campus clinics. Questions were designed to guide the focus group, with questions remaining open-ended to facilitate interaction among students (Creswell, 2007).

Attendance at the focus group was mandatory for all students enrolled in the on-campus clinic course. Both the adjunct faculty supervising in the clinic and the companion didactic course faculty, who encouraged responses from all participants and guided discussion that built on student responses, facilitated the focus group. The researcher analyzing the data was not present in all focus groups. A student participant in the course typed responses throughout the focus group discussion. The typed responses were viewed by all students and faculty involved in the focus group, which provided opportunity for verification of recorded responses.

The quantitative data on the survey, the open-ended survey questions, and the focus group discussions allowed for concurrent triangulation with comparison of the quantitative and qualitative data analyses to validate the findings (Creswell, 2003). Survey responses to the open-ended questions were triangulated with data from focus group results. Qualitative data analysis was done by hand and all responses from the survey questions and the focus group questions were collated within each question. Responses within each question were analyzed for word repetition, which were colorcoded based on content of responses until significant statements emerged from those word repetitions. Those significant statements were then grouped into themes. 


\section{RESULTS}

Four statements from the quantitative section of the survey were analyzed to validate the qualitative themes that emerged in the data analysis: served as a positive role model of professional behavior, encouraged student self-directed learning, facilitated student's clinical reasoning, and modeled occupation-centered practice. Frequencies in the adult on-campus clinic cohorts and pediatric on-campus clinic cohorts were calculated for students' level of agreement on the four qualitative themes. Findings were similar across both adult and pediatric clinics with the majority agreeing or strongly agreeing to the role of faculty in these four areas (see Table 1).

Table 1

Student Percentages for Faculty Educator Role in Adult $(n=124)$ and Pediatric $(n=129)$ On-Campus Clinic

\begin{tabular}{|r|c|c|c|c|c|}
\hline & $\begin{array}{c}\text { Strongly } \\
\text { agree }\end{array}$ & Agree & Neutral & Disagree & $\begin{array}{c}\text { Strongly } \\
\text { disagree }\end{array}$ \\
\hline \begin{tabular}{|} 
Provided positive role \\
model
\end{tabular} & & & & & \\
$\begin{array}{c}\text { Adult Clinic } \\
\text { Pediatric Clinic }\end{array}$ & $68 \%$ & $24 \%$ & $7 \%$ & $0 \%$ & $1 \%$ \\
\hline $\begin{array}{c}\text { Encouraged student } \\
\text { self-directed learning } \\
\text { Adult Clinic }\end{array}$ & $50 \%$ & $44 \%$ & $7 \%$ & $1 \%$ & $0 \%$ \\
Pediatric Clinic & $51 \%$ & $44 \%$ & $5 \%$ & $0 \%$ & $1 \%$ \\
\hline $\begin{array}{c}\text { Facilitated student's } \\
\text { clinical reasoning }\end{array}$ & & & & & \\
Adult Clinic & $47 \%$ & $45 \%$ & $6 \%$ & $1 \%$ & $1 \%$ \\
Pediatric Clinic & $45 \%$ & $41 \%$ & $11 \%$ & $4 \%$ & $0 \%$ \\
\hline $\begin{array}{c}\text { Modeled occupation- } \\
\text { centered practice }\end{array}$ & & & & & \\
Adult Clinic & $49 \%$ & $41 \%$ & $6 \%$ & $2 \%$ & $2 \%$ \\
Pediatric Clinic & $55 \%$ & $39 \%$ & $6 \%$ & $1 \%$ & $0 \%$ \\
\hline \multicolumn{2}{|c|}{} & & & & \\
\hline
\end{tabular}

Mean scores of students rating the role faculty for each of the five years of the adult oncampus clinic and each of the five years of the pediatric on-campus clinic were calculated. All mean scores were 4.0 or higher therefore no inferential statistics were calculated. Figures 1 and 2 show the consistency of agreement within cohorts across fall and spring semester that faculty were positive role models of professional behavior, encouraged self-directed learning, facilitated clinical reasoning, and modeled occupation-centered practice. 

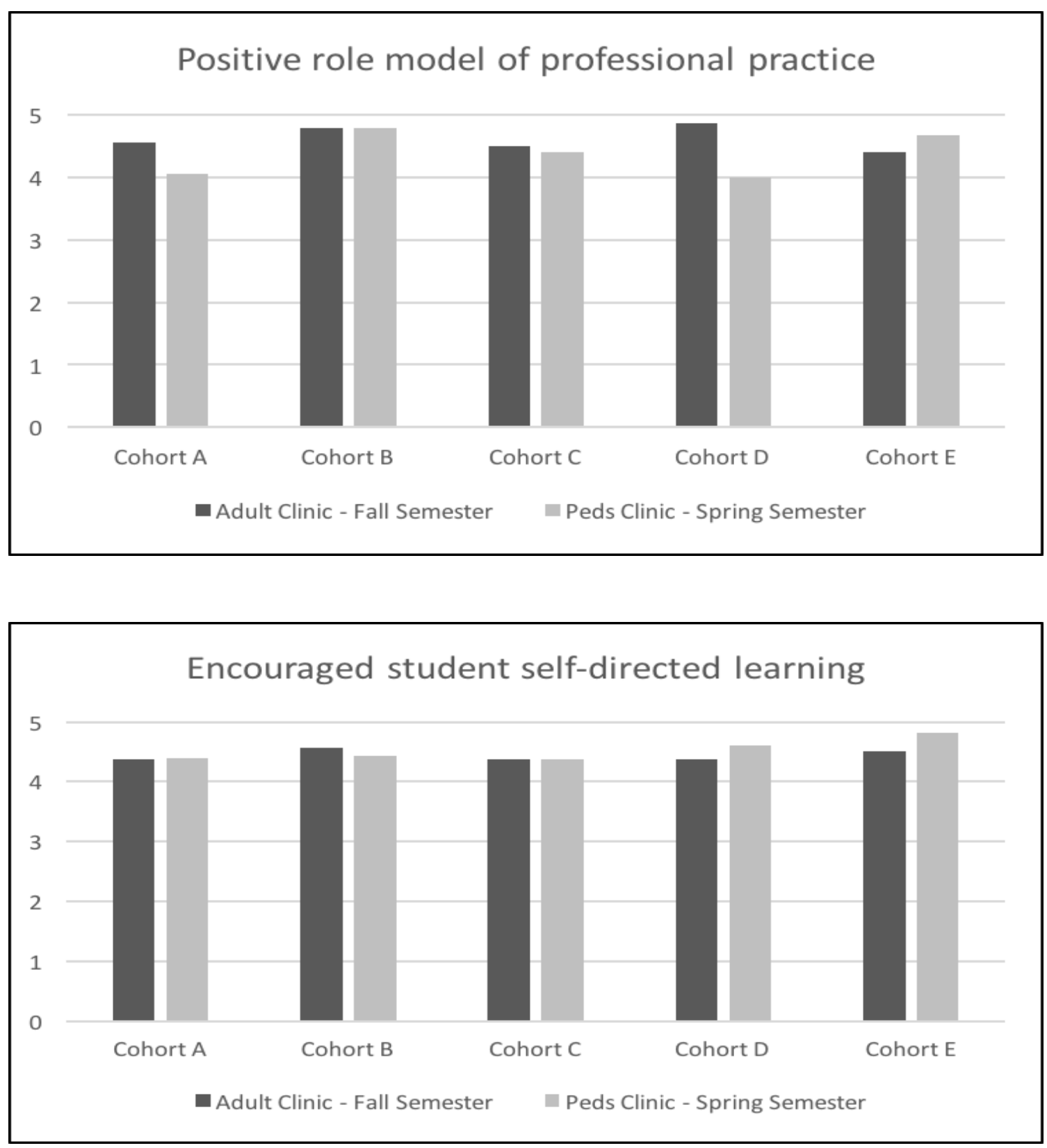

Figure 1. Student perception of faculty role in the on-campus clinic course to provide a positive role model and to encourage self-directed learning. A 5-point Likert scale ( $1=$ strongly disagree, 5 = strongly agree) was used. Each cohort represents student responses in fall semester followed by spring semester. Cohort $A$ adult clinic $(n=21)$, peds clinic $(n=20)$; Cohort B adult clinic $(n=25)$, peds clinic $(n=25)$; Cohort $C$ adult clinic $(n=26)$, peds clinic $(n=27)$; Cohort $D$ adult clinic $(n=30)$, peds clinic $(n=15)$; Cohort $E$ adult clinic $(n=22)$, peds clinic $(n=27)$. 

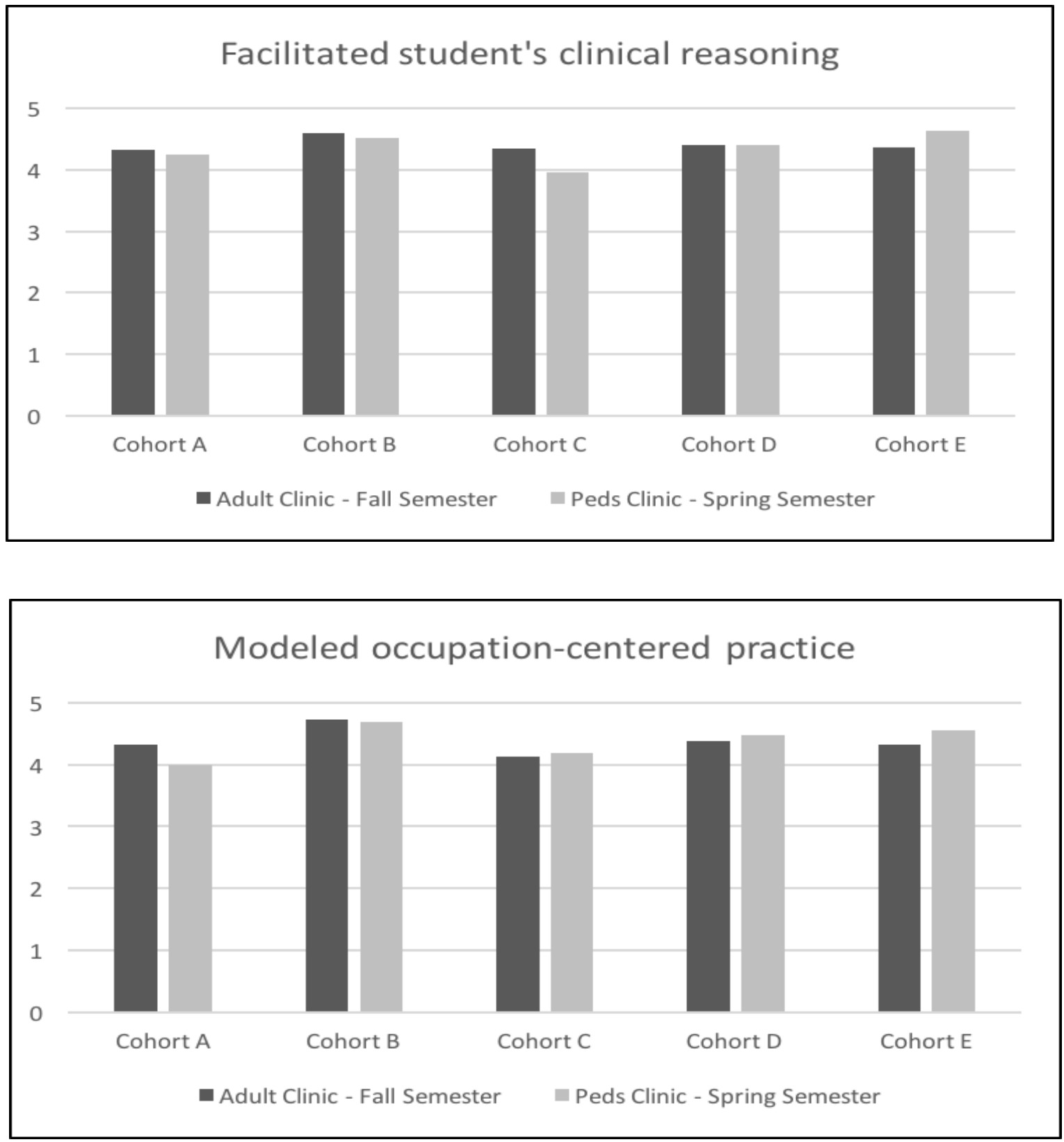

Figure 2. Student perception of faculty role in the on-campus clinic course to facilitate clinical reasoning and to model occupation-centered practice. A 5-point Likert scale $(1=$ strongly disagree, 5 = strongly agree) was used. Each cohort represents student responses in fall semester followed by spring semester. Cohort $A$ adult clinic $(n=21)$, peds clinic $(n=20)$; Cohort B adult clinic $(n=25)$, peds clinic $(n=25)$; Cohort $C$ adult clinic $(n=26)$, peds clinic $(n=27)$; Cohort $D$ adult clinic $(n=30)$, peds clinic $(n=15)$; Cohort $E$ adult clinic $(n=22)$, peds clinic $(n=27)$. 
Qualitative analysis revealed four distinct themes among students' perspectives: internal well-being, ability to adapt, contribution to learning, and professionalism emerged from the qualitative data.

\section{Internal Well-being}

Students reported comfort, confidence, and self-directed learning through comments that supported the theme of internal well-being. The terms comfort or confidence were directly used in 113 statements from participants in both the survey and focus groups. Students specifically identified increased confidence and comfort with skills, ability, and knowledge. One participant stated, "The clinic really helped me grow and gave me confidence in the skills I have been learning" while another reported "Working with a client has given me much more confidence in myself and my current knowledge and skills."

Further, students gained confidence and comfort with intervention planning and implementation, including interacting with clients and family members. One participant indicated that he or she "gained comfort and confidence of working hands-on with patients. Feel confident to transition to a real clinic setting." Another participant reported that they "gained more confidence and learned to think more on my feet as well as clinically to increase my judgment in regards to client's functioning." A third participant cited "increased confidence in giving assessments, planning interventions, observing behaviors, [and] carrying out intervention plans." This quote from a participant shows the importance of an extended clinical experience within the curriculum:

Going into clinic I did not have confidence in myself and was intimidated of the client. By the end of the 10 weeks, I have more confidence in working with kids, planning interventions, and am just starting to feel more comfortable with the thought of the intervention plan not going as I thought.

Self-directed learning was also an important outcome that supported the student's sense of internal well-being. Self-directed learning was more difficult for some: "For the most part [the pediatrics didactic course] did not coincide with my client and interventions that were carried out in our therapy sessions [in the pediatric clinic]." The qualitative theme of internal well-being was validated with quantitative survey results indicating agreement that the faculty encouraged student self-directed learning: the adult on-campus clinic reported a 4.44 mean score across cohorts and the pediatric oncampus clinic reported a 4.52 mean score across cohorts.

Accessing resources was identified as a particular component in enhancing selfdirected learning. One participant stated, "I've learned how to better utilize my resources in the clinic and in textbooks, and helped me feel Fieldwork II ready!" While another participant stated, "All of my interventions derived from things I learned [in the pediatrics didactic course] and resources that were provided... I got many ideas from that course that enabled me to do my own research and work outside of class." Multiple student responses were able to identify the value of connecting evidence-based concepts in coursework to application in the clinic. One participant stated, "I became more 
independent in my learning and took on the role of searching for my own resources for evidence-based interventions." Another participant noted the challenges of self-directed learning: "It really challenged me and gave me additional opportunities to investigate what I have learned. I appreciated taking information from article searches and apply them to my client." One participant enjoyed the challenge of evidence-based practice in the clinic: "It was fun to research and create my interventions based on the evidencebased practice described in the [neurorehabilitation course] textbooks."

\section{Ability to Adapt \\ Flexibility and adjusting to situations were common in the theme of ability to adapt. Students identified: "I learned to think on my toes and that you can adapt a lot to individuals' needs" and "I feel that I have become more flexible when there were multiple clients at the same time." One participant also identified, "I increased my ability to grade activities in the moment." Another participant stated, "The certain characteristics of diagnoses were helpful to know in determining how to adjust my approach while working with my client who had a neurological [diagnosis]."}

Students identified that what is learned in didactic courses often needs to be modified when applied with clients in clinical settings. "[Seeing] that clients aren't always a text book description" and "how to apply what you learned was good to see that not everything is done by the book." One participant indicated "...coursework does not always apply. Our clients have unique circumstances" suggesting that this student identified the need to adapt concepts learned in academic work to fit the actual needs of clients.

\section{Contribution to Learning}

Students identified that the on-campus clinic experience enhanced their learning of building rapport, managing time effectively, gaining hands-on experience, and preparing for Level II fieldwork. Enhanced clinical reasoning also came through in the comments as a significant outcome from the students' experiences. One participant stated, "I grew in my clinical reasoning because of the amount of thinking, planning, and quick changes I had to do." Another participant stated, "My clinical reasoning has improved greatly throughout the clinic session. I have learned to try new things and I now have a better handle on how to document using my clinical reasoning."

The statements supporting enhanced clinical reasoning were validated with quantitative survey results indicating agreement that the faculty facilitated development of clinical reasoning: the adult on-campus clinic reported a 4.41 mean score across cohorts and the pediatric on-campus clinic reported a 4.35 mean score across cohorts.

The following quotes indicate the importance of reflection to developing clinical reasoning and the connections participants drew between the on-campus clinics and Level II fieldwork preparation: "I developed my clinical reasoning skills to prepare for fieldwork. I was able to work directly with a pediatric patient which built on my clinic experience from previous semesters and fieldwork"; "The experience required a lot of creativity as well as a lot of reflection. The demands of the experience helped me put 
my education into practice"; and "It's just great to have the experience and be able to learn from your mistakes in a way that isn't possible in a Fieldwork II experience."

Students identified value in being able to share experiences with other classmates through observations and informal discussions as well as participating in more structured discussions in class or within clinic, which facilitated students' active reflection. One participant identified the experience "allowed me to apply what I learned and to learn from my peers when they described their experiences." Another participant identified "...the opportunity to hear other students' interventions, thoughts, and experiences was also beneficial in applying and critically thinking as [an] OTS."

Responses indicated that students were able to bring information from class to clinic and experiences from clinic to classroom learning. The value of being able to apply concepts learned in class through an actual client experience was evident with 77 responses specifically identifying phrases such as hands-on learning, applying, or real/actual application. Several responses indicated that students could easily apply concepts learned in the didactic courses within the clinics. "The experience from working with my clinic client helped me think critically about the information we were learning in [the pediatric course] as well as add information to class discussions" and the information that I learned [in the pediatric course] greatly helped my sessions with my client and from working with my client, I was able to provide examples to help my classmates." One participant stated, "We were able to use ideas from class to support our reasoning behind the interventions." A second participant stated: "The experience allowed me to take what I was learning and get hands on experience with applying that knowledge while having the support and guidance of occupational therapists. This was an invaluable experience... I know from having now actually had the experience that I could not have learned what I did through books alone. I have a better understanding of myself because of this experience."

Some students made connections of how multiple didactic courses integrated with the clinic experience supported with this statement from the pediatric clinic experience: "I also had to review a lot of the notes and resources used in Neurorehab from the fall as my client's diagnosis was discussed in Neuro. But then I was challenged to apply the Neuro information to the pediatric population and re-design interventions for adults that were age-appropriate..."

Data gathered from the students' perceptions of the connection of learning from the didactic course and the clinic experience was helpful in identifying how faculty need to be explicit in making connections for students. For example, students stated: "It was hard to relate [the neuro course] to a client with a disability that was not covered in class"; "The clients didn't always match the neuro descriptions"; and "The only thing that I thought correlated were our client's psychosocial issues, which we only discussed in one neurorehab lecture." 


\section{Professionalism}

Working with peers and the role of the faculty in the clinical process supported the theme of professionalism. Students indicated they became better at working with a partner and delegating tasks. Specifically, students identified: "Working with a partner that I had not previously worked with also increased my growth and development as it provided me with a new kind of insight and another person's thought processes that I had not yet been exposed to"; "I communicated with the other two classmates about switching rooms or [using different spaces]. In addition, using the communication board was very effective and I learned to refer to this first, before asking questions of another person or attempting to find a .... piece of equipment"; and "I've really learned the number of people that you have to communicate with in a clinical setting."

Students specifically identified support, guidance, and feedback from the faculty as important in the on-campus clinic experience. Students identified the following about support and guidance from the faculty: "[My supervisor] allowed me opportunity to bounce ideas off her and was always receptive to questions"; "My supervisor really supported me in reflecting on what did and did not work during my sessions in terms of interventions and in terms of therapeutic use of self"; and "I was nervous [about] the clinic supervisor in the room critiquing me. I now realize how nice it was to have the clinic supervisor in the room because now was the time I could make mistakes and learn from them."

Three students also noted the amount of feedback and the importance of clarity of expectations as important to the experience: "I appreciate all of the advice and feedback. But initially I felt I was not filling standards due to so much feedback" and "Feedback was helpful, but sometimes difficult to understand what was needed exactly." Another student reported "Feel like the positive and constructive feedback helped increase my level of confidence." The statements supporting professionalism were validated with quantitative survey results indicating agreement that faculty served as positive role models of professional practice: the adult on-campus clinic reported a 4.63 mean score across cohorts and the pediatric on-campus clinic reported a 4.39 mean score across cohorts.

\section{DISCUSSION}

The theme of internal well-being shows that students gained confidence in skills and knowledge for intervention planning and implementation by participating in the oncampus clinic is similar to the findings of other studies (Benson et al., 2013; Coker, 2010; Goldbach \& Stella, 2017; Falk-Kessler et al., 2007; Knecht-Sabres, 2013). While improved self-confidence, enhanced perceptions of clinical reasoning, and improved planning of interventions and treatment sessions have consistently been shown across these studies, the current study demonstrates that this outcome is sustainable over five years of students.

The theme of ability to adapt identified that students were able to develop the skill of modifying theoretical concepts. Previous research found that students in a community setting experiential were "able to think about the unique aspects of the client's 
situation..." (Knecht-Sabres, 2013, p. 29). The findings here suggest that this same type of student learning is possible in an on-campus clinic experience sustained over several years. The ability to adapt clinical knowledge to match client needs is often challenging as students tend to be more rigid in their application of theoretical principles in the development of clinical skills (Dreyfus \& Dreyfus, 1980; Unsworth, 2001). An on-campus clinic experiential appears to be beneficial in students developing skill acquisition for greater flexibility and adaptability.

Reflection was one of the main components identified as important in experiential learning opportunities with clients. The findings of the current study indicate that an embedded on-campus clinic experience with didactic coursework allows various opportunities for reflection. The theme of contribution to learning supports that reflection appeared to be beneficial in enhancing a student's perceived abilities in clinical reasoning. This theme also clearly showed the frequency of students connecting didactic classroom work with actual client situations, which supports the findings of previous studies (Benson et al., 2002; Falk-Kessler et al. 2007).

Students repeatedly identified feeling more prepared and more aware of their own needs in preparation for Level II fieldwork, which emerged in the theme contribution to learning and was similar to the findings of Goldbach and Stella (2007). The finding may be related to the enhanced clinical reasoning and increased confidence that students experienced with the on-campus clinics. This finding may also be related to the enhanced understanding of the role of the clinical educator and from participating in the student-clinical educator relationship firsthand.

Students identified that faculty modeling behaviors and integrating clinical reasoning into the classroom was beneficial as a part of this on-campus clinic, which is an important benefit of experientials with clients (Benson et al., 2002; Neistadt, 1996). Understanding how to work well with supervisors and peers in a clinical setting is important in developing professionalism and the on-campus clinic experiential in this study supported that development. Students identified that the faculty in the clinic were important in providing feedback, support, and guidance throughout the clinic experience, further enhancing understanding of the faculty-student relationship. Given this important role modeling by faculty suggests the need to be aware of the impact faculty will have on students, and to understand that the faculty role is crucial in students' success (Haertl, 2008).

\section{LIMITATIONS AND FUTURE RESEARCH}

The use of a self-designed survey limits the reliability and validity of the quantitative study findings. Further, the longevity of the study provides some benefits to consistency in data analysis yet also allowed for a non-homogenous sampling based on cohort sizes varying over the years and faculty changes with differed styles in supervising students. Future studies should consider the impact of mandatory participation in focus groups as a course requirement and implement voluntary participation. Further studies should address long-term outcomes among students with measuring Level II fieldwork competency and program completion with certification. 
A significant finding of this study was the perception of enhanced internal well-being through improved comfort and confidence for students. Strategies to validate these findings through quantitative methods should be explored, specifically identifying what components of the experiential opportunity lead to changes. Further studies should implement pre- and post-testing to determine actual changes in students' clinical reasoning and professional skill development.

\section{IMPLICATIONS FOR OCCUPATIONAL THERAPY EDUCATION}

The findings here suggest a benefit to having an on-campus clinic experience with the value of concurrent experiences when students engage in didactic course activities and clinic experiences in the same week to allow for active reflection and application in both experiences. The clear value of the role of the faculty in the on-campus clinic experience becomes apparent when students and faculty are working side-by-side in client sessions. Faculty also enhance students' integration of theoretical knowledge and clinical experiences.

An on-campus clinic occurring within the didactic curriculum long-term is feasible and beneficial as shown in these findings, which eliminates many of the barriers with offcampus experientials: finding a site that is flexible, managing transportation to the site, scheduling time for commuting to the site, and meeting the extra demands on faculty time to administer the experiential (Benson et al., 2002; Falk-Kessler et al., 2007; Knecht-Sabres, 2013). Holding an on-campus clinic allows easier access to the clinic site for faculty and students and potentially decreases the costs in time and resources to utilize the clinic site. Further, this on-campus clinic had consistent support from program and administration, which may have contributed to the long-term implementation in the curriculum.

The enhanced confidence and improved clinical reasoning the students experienced as a result of the on-campus clinic experience likely contributes to students feeling more prepared for Level II fieldwork. This has implications for easing placement of students for Level II fieldwork as community sites may find students more prepared for the pace and demands. The on-campus clinic experience presented here also may address the identified challenges in programs: finding fieldwork sites and bridging the gap between education and practice. Exploring and implementing hands-on learning experiences with clients in occupational therapy curriculum may be an opportunity to contribute to modifying fieldwork education structure. The findings support the feasibility of implementing an on-campus clinic that shows positive student outcomes and enhanced faculty-student relationships across several years.

\section{References}

American Occupational Therapy Association Fieldwork Ad Hoc Committee. (2017).

Fieldwork (experiential learning) Ad Hoc Committee report and recommendations to the AOTA Board of Directors. Retrieved from https://www.aota.org/ /media/Corporate/Files/EducationCareers/Educators/Field work/AOTA-Fieldwork/Residency-for-OTs-considered-by-AOTA-ad-hoccommittee-report.pdf 
Benson, J. D., Provident, I., \& Szucs, K. A. (2013). An experiential learning lab embedded in a didactic course: Outcomes form a pediatric intervention course. Occupational Therapy in Health Care, 27(1), 46-57. https://dx.doi.org/10.3109/07380577.2012.756599

Coker, P. (2010). Effects of an experiential learning program on the clinical reasoning and critical thinking skills of occupational therapy students. Journal of Allied Health, 39(4), 280-286. Retrieved from http://www.asahp.org/journal-of-allied-health/

Creswell, J. W. (2003). Research design: Qualitative, quantitative, and mixed methods approaches ( $2^{\text {nd }}$ ed.). Sage Publications: Thousand Oaks, CA.

Creswell, J. W. (2007). Qualitative inquiry \& research design: Choosing among five approaches ( $2^{\text {nd }}$ ed.). Sage Publications: Thousand Oaks, CA.

Dreyfus, S. E., \& Dreyfus, H. L. (1980). A five-stage model of the mental activities involved in directed skill acquisition (No. ORC-80-2). California University Berkeley Operations Research Center. https://doi.org/10.21236/ADA084551

Falk-Kessler, J., Benson, J. D., \& Witchger Hansen, A. M. (2007). Moving the classroom to the clinic: The experiences of occupational therapy students during a "living lab". Occupational Therapy in Health Care, 21(3), 79-91. https://doi.org/10.1300/j003v21n03 05

Goldbach, W. P., \& Stella, T. C. (2017). Experiential learning to advance student readiness for Level II fieldwork. Journal of Occupational Therapy Education, 1(1). https://doi.org/10.26681/jote.2017.010103

Haertl, K. (2008). From the roots of psychosocial practice-therapeutic use of self in the classroom: Practical applications for the occupational therapy faculty. Occupational Therapy in Mental Health, 24(2), 121-134. https://doi.org/10.1080/01642120802055168

Kinchin, I. M., Baysan, A., \& Cabot, L. B. (2008). Towards a pedagogy for clinical education: Beyond individual learning differences. Journal of Further \& Higher Education, 32(4), 373-387. https://doi.org/10.1080/03098770802395587

Knecht-Sabres, L. J. (2013). Experiential learning in occupational therapy: Can it enhance readiness for clinical practice? Journal of Experiential Education, 36(1), 22-36. https://doi.org/10.1177/1053825913481584

Kolb, A. Y., \& Kolb, D. A. (2005). Learning styles and learning spaces: Enhancing experiential learning in higher education. Academy of Management Learning \& Education, 4(2), 193-212. https://doi.org/10.5465/amle.2005.17268566

Lee, A. (2007). How can a mentor support experiential learning? Clinical Child Psychology and Psychiatry, 12(3), 333-340. https://doi.org/10.1177/1359104507078455

Neistadt, M. E. (2996). Teaching strategies for the development of clinical reasoning. American Journal of Occupational Therapy, 50(8), 676-684. https://doi.org/10.5014/ajot.50.8.676

Nolinske, T. \& Millis, B. (1999). Cooperative learning as an approach to pedagogy. American Journal of Occupational Therapy, 53(1), 31-40. https://doi.org/10.5014/ajot.53.1.31 
Peloquin, S. M., \& Osborne, K. A. (2003). Establishing a practice climate in academic settings. Journal of Allied Health, 32(2), 78-85. Retrieved from http://www.asahp.org/journal-of-allied-health/

Phillips, E. A. (2017). Evaluation of a coaching experiential learning project on OT student abilities and perceptions. Open Journal of Occupational Therapy, 5(1). https://doi.org/10.15453/2168-6408.1256

Unsworth, C. A. (2001). The clinical reasoning of novice and expert occupational therapists. Scandinavian Journal of Occupational Therapy, 8(4), 163-173. https://doi.org/10.1080/110381201317166522 